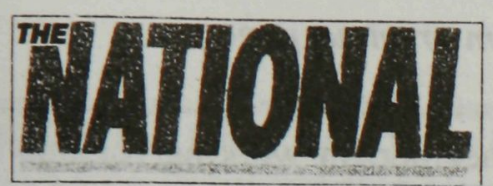

\title{
Political guidelines
}

ADDITIONAL guidelines that The National set for its reporters to follow in coverage of political stories during the June general election. Jurisdiction:

The National will not publish in its news columns comments by politicians about an area that is outside of his or her jurisdiction. That means that no Member of Parliament would be recognised as making a newsworthy statement if he were to make claims about an electorate other than his own or about a ministry other than his own. He can, however, reply to criticisms or claims against him by somebody who has jurisdiction. That rule will be applied less stringently in letters and advertisements. The Prime Minister and the alternate Prime Minister will be allowed to make wide-ranging comments on all issues.

\section{Changing political affiliations:}

Any Member of Parliament who claims he has shifted allegiances must be able to confirm that he has done so in the presence of the new party leader. He must provide documentary evidence that he has actually signed up with the new party. He must provide a fairly detailed brief as to why he is moving from one party to the other.

\section{Personal attacks and allegations:}

All claims which names an individual will not be published until the opinion of the person named has been sought.

\section{Trips:}

All trips offered by political parties will be approved by the editor. Anybody making an unauthorised trip will be seen to be making a personal trip and if that is in company time the right disciplinary procedures will be applied.

\section{Gifts:}

Offers of cash, hotel accommodation, dinners, drinks and any other gifts in exchange for publication of news items or anything else must be reported to the editor immediately. If it is not and the editor learns of it, company will take it as a serious breach of ethics and as misconduct. 


\section{NATIONAL GUIDELINES From previous page}

\section{Requesting favours:}

No journalist or photographer or any other person working for this organisation can likewise make a request for any favours in exchange for publication of news items, photographs or anything else.

\section{Selling information:}

No item of news gathered by an employee of this company can be given, sold or published in any other medium before The National, the breach of which will be viewed as a serious breach of discipline, ethics and terms and conditions of employment.

\section{Biased reports:}

No news item should be deliberately written to misconstrue the actual situation, be biased, carry untruths or be slanted in favour of or against any individual, group or community. Proof of this will mean very serious disciplinary charges, To avoid inadvertent slants, people who are too involved in a story or with a group must declare to the editor that they have been so involved in order that the job is reassigned or the finished story is screened closely.

All journalists should know and adhere to the journalists code of ethics and to apply those in their work.

The above are general guides. The editor may, in his absolute discretion, vary these rules in special circumstances.

Features: Features, analysis, commentaries, profiles and interviews will also be run if they satisfy the general rules of fair comment, public interest and are not grossly misleading or against public decency.

Advertisements: No advertisement will be run that is unfair, untrue, is designed to raise public hatred or stir unrest in the community or clearly defames any person, institution or community.

Photographs: All above rules apply to photographs.

$\square$ Frank Senge Kolma is Editor of The National. He presented this paper at the 'Ombudsman Commission and the Media:Transparency and Accountability' seminar in Port Moresby on 14 May 1997. 